\title{
Polyvinyl Alcohol-Alginate Adsorbent Beads for Chromium (VI) Removal
}

\author{
${ }^{1,3}$ Lee Te Chuan, ${ }^{2}$ Norpadzlihatun Manap, ${ }^{3}$ Hasan Zuhudi Abdullah and ${ }^{3}$ Maizlinda Izwana Idris \\ ${ }^{I}$ Department of Production and Operation Management, Faculty of Technology Management and Business, Universiti Tun Hussein Onn \\ Malaysia, 86400 Batu Pahat, Johor, Malaysia \\ ${ }^{2}$ Department of Construction Management, Faculty of Technology Management and Business, Universiti Tun Hussein Onn Malaysia, \\ 86400 Batu Pahat, Johor, Malaysia \\ ${ }^{3}$ Department of Materials Engineering and Design, Faculty of Mechanical and Manufacturing Engineering, Universiti Tun Hussein Onn \\ Malaysia, 86400 Batu Pahat, Johor, Malaysia. \\ Corresponding Arthur E-mail: tclee@uthm.edu.my
}

\begin{abstract}
Chromium pollution has been an increasing concern worldwide because of its high toxicity and carcinogenic properties, and it requires an efficient purification technique. In this study, adsorbent beads containing polyvinyl alcohol (PVA) and sodium alginate were prepared by crosslinking with boric acid and calcium chloride for adsorbent of the hexavalent chromium [Cr (VI)]. Batch adsorption studies were conducted to evaluate $\mathrm{Cr}$ (VI) adsorption rates of PVA-alginate beads from aqueous solution under ultraviolet (UV) light illumination. The surface morphology and elemental composition of beads were examined using field emission scanning electron microscopy (FESEM) and energy dispersive spectrometer (EDS), respectively. This study revealed that the Cr (VI) adsorption rates increased remarkably with dosages of PVA and sodium alginate. This occurred mainly due to the increasing number of the active sites for adsorption. The results revealed that adsorbent beads with $12 \mathrm{~g}$ of PVA and $2.5 \mathrm{~g}$ sodium alginate beads exhibited superior Cr (VI) adsorption efficiency at which it is completely removed after 1.5 hours. The findings of this study indicate that PVA-sodium alginate beads are a viable option for $\mathrm{Cr}$ (VI) removal from industrial wastewater.
\end{abstract}

Keywords: Polyvinyl alcohol, Sodium alginate, Adsorbent beads, Chromium (VI), UV illumination

\section{Introduction}

Heavy metal pollution is a critical environmental issue, predominantly due to the discharge of industrial wastes. Heavy metals such as chromium, mercury, lead, arsenic, and cadmium are highly toxic, and threaten the human health and environment [1].

Chromium pollution has been an increasing concern worldwide for the last few decades, especially due to the wastes from chemical industries for electroplating, leather tanning, painting processes, and mining industries. Chromium exists in several oxidation states ranging from -2 to +6 . Among these, $\mathrm{Cr}$ (III) and $\mathrm{Cr}$ (VI) are the most stable forms of chromium. $\mathrm{Cr}$ (VI) is approximately 100 times more acutely toxic comparison with $\mathrm{Cr}$ (III) owing to the existence of hydrogen chromate $\left(\mathrm{HCrO}^{4}\right)$ and dichromate $\left(\mathrm{Cr}_{2} \mathrm{O}_{7}^{2-}\right)$ Because of its carcinogenic properties and high toxicity, $\mathrm{Cr}(\mathrm{VI})$ causes diseases such as lung cancer, skin rashes, respiratory problems, vomiting, weakened immune system, epigastric pain, nausea, kidney and liver damage, and alternation of genetic materials [16]. Additionally, high level of $\mathrm{Cr}$ (VI) in underwater sediments can lead to chromium pollution which can affect the fishes and benthos during anthropogenic activities, at which including dredging [15]. As stated in several environmental laws and regulations, the maximum permissible concentration of the chromium is $0.05 \mathrm{mg} / \mathrm{L}$ ([19]; [23]).

There are various techniques that have been implemented for metal recovery operations and water purification, for instance, electro-deposition, activated carbon, semiconductor-based photocatalysis, chemical precipitation, reverse osmosis, cementation, ion exchange, and adsorption [2]. Of all the aforementioned techniques, adsorption has attracted the greatest deal of interest owing to its many advantages such as various choices of adsorbent materials, cost effectiveness, and high efficiency [10].

Biopolymers are sought-after adsorbent material owing to its capability of lower transition, wide availability, non-toxicity, and being environmentally friendly. The choice of biopolymers as adsorbent material is strongly dependent on the chemical composition of the heavy metal solution, types of metals being adsorbed, quality of by-product, efficiency, and the cost effectiveness [21]. Alginate is a well-known abundantly available marine biopolymer. It can be extracted from intracellular spaces or cell walls of brown seaweed [5]. It had been proven that sodium alginate-based beads perform excellent adsorption abilities for the heavy metals such as cadmium, lead, chromium, and arsenic ([3]; [16]; [20]). It is noteworthy to mention that sodium alginate also possess remarkable potential as adsorbent material for radioactive wastes ([6]; [22]). 
On the other hand, polyvinyl alcohol (PVA) is a highly soluble, biodegradable with mechanical stability, high diffusivity, and chemical stability of a synthetic polymer. PVA is produced from the hydrolysis of polyvinyl acetate. PVA can be dissolved in water easily due to the existence of hydroxyl groups in its chemical structure ([8]). Similar to sodium alginate, PVA also possesses excellent adsorption abilities. Moreover, PVA is a synthetic polymer suitable for the formulation of blends with natural polymers owing to its high polarity and water solubility ([12]; [13])

In the present study, PVA-alginate beads were prepared and utilised in the adsorption of Cr (VI). The effect of different dosages of PVA and sodium alginate on the adsorption of $\mathrm{Cr}$ (VI) from an aqueous solution was also investigated. In term of practicality, this study is beneficial especially for the further applications of alginate beads in wastewater treatment technology.

\section{Methodology}

\subsection{Preparation of PVA-Alginate Beads}

PVA (Acros Organics) with various dosage (3-12 g) was added into $53 \mathrm{~mL}$ of distilled water and heated using microwave at $100{ }^{\circ} \mathrm{C}$ for 1 minute. Meanwhile, sodium alginate (Q'rec) with various dosages $(0.5-2.5 \mathrm{~g})$ was stirred with magnetic stirrer in $20 \mathrm{~mL}$ of distilled water until completely dissolved. Subsequently, the PVA gel was mixed with sodium alginate gel by continuous stirring to achieve homogenous gel. The syringe needle was used to produce PVA-sodium alginate beads then dropped into the crosslink solution comprising of $6 \%$ boric acid (Q'rec) and $2 \%$ calcium chloride (Q'rec) under continuous stirring. The PVA-alginate beads were kept in the crosslink solution for 24 hours in order to allow them to cure and ensures sufficient gelation reaction time for the beads. Subsequently, the excess borate ions on the surface of beads were removed by repeated washing with distilled water [13]. The PVA-alginate beads were then treated with $0.5 \mathrm{M}$ sodium sulphate (Q'rec) for 30 minutes to enhance its mechanical properties and chemical stability. In order to avoid the internal structure from collapsing, the PVA-alginate beads were stored wet at the temperature of $4{ }^{0} \mathrm{C}$ for further use.

\subsection{Batch Adsorption Studies}

$15 \mathrm{~g}$ (wet weight) of PVA-alginate beads were put into $50 \mathrm{~mL}$ of $50 \mathrm{ppm} \mathrm{Cr}$ (VI) in a beaker. The adsorption experiment was conducted under UV illumination at ambient temperature. The distance between UV lamp (184-watt, $365 \mathrm{~nm}$, Philips) and beaker was maintained at $15 \mathrm{~cm} .5 \mathrm{~mL}$ of sample was collected every 30 minutes during the whole period of the batch experiment and tested for $\mathrm{Cr}(\mathrm{VI})$ concentration.

\subsection{Chromium (VI) Analysis.}

The concentration of chromium (VI) was examined using Diphenylcarbazide (DPC) method. $1 \mathrm{~mL}$ of sample taken from batch experiment was then mixed with $0.2 \mathrm{~mL}$ of freshly prepared $0.25 \%(\mathrm{w} / \mathrm{v})$ DPC (Q'rec) in acetone (Merck Schuchardt $\mathrm{OHG}$ ), and $9 \mathrm{~mL}$ of $0.2 \mathrm{M} \mathrm{H}_{2} \mathrm{SO}_{4}$ (Merck Schuchardt $\mathrm{OHG}$ ) in a volumetric flask. Subsequently, the mixture solution was vortexed for 15-30 seconds and stand for 10-15 minutes to achieve full colour development. UV-Visible spectrometer (Thermo Scientific) at wavelength of $540 \mathrm{~nm}$ was used to measure the concentration of chromium (VI). Equation 1 was used to determine the $\mathrm{Cr}$ (VI) reduction rate of PVAalginate beads ([14]).

$\mathrm{Cr}(\mathrm{VI})$ reduction rate $(\%)=\left[\left(\mathrm{C}_{\mathrm{o}}-\mathrm{C}\right) / \mathrm{C}_{\mathrm{o}}\right] \times 100 \%$

$\mathrm{C}_{\mathrm{o}}=$ initial concentration; $\mathrm{C}=$ final concentration

\subsection{Characterisation.}

The surface morphology of the PVA-alginate beads was examined using field emission scanning electron microscopy (FESEM, JFM-7600F, JEOL, $1 \mathrm{kV}$ ). The elemental composition was examined using energy dispersive spectrometer (EDS, XMX0034, JEOL, 1 kV).

\section{Results and Discussion}

Figure 1 shows the $\mathrm{Cr}$ (VI) adsorption rate of PVA-alginate beads produced from $0.5 \mathrm{~g}$ sodium alginate and varying dosages of PVA (3-12 g). It could be seen that the adsorption efficiency has increased remarkably with the increase of PVA dosage. When the dosage of PVA was $3 \mathrm{~g}, \mathrm{Cr}$ (VI) has not been completely removed by beads, at which only $88 \%$ of $\mathrm{Cr}$ (VI) was adsorbed after 4 hours of illumination time. However, as the dosage of PVA increased to $6 \mathrm{~g}, 9 \mathrm{~g}$ and $12 \mathrm{~g}$, there was a significant increase in the $\mathrm{Cr}$ (VI) adsorption efficiency, at which $97 \%$ and $100 \%$ of Cr (VI) were adsorbed by 6 g PVA$0.5 \mathrm{~g}$ alginate beads and $9 \mathrm{~g}$ PVA- $0.5 \mathrm{~g}$ alginate beads, respectively. When the dosage of PVA was increased to $12 \mathrm{~g}$, The Cr (VI) was observed to be totally removed from aqueous solution after 3 hours of illumination time. The excellent performance of $\mathrm{Cr}$ (VI) adsorption at a higher dosage of PVA is mainly attributed to the increasing number of the active sites and possible sites [7]. Comparable results were also obtained by [9]. They reported that the increased of the PVA dosage enhances the adsorption capacity of $\mathrm{Cd}$ (II) in aqueous solution. 


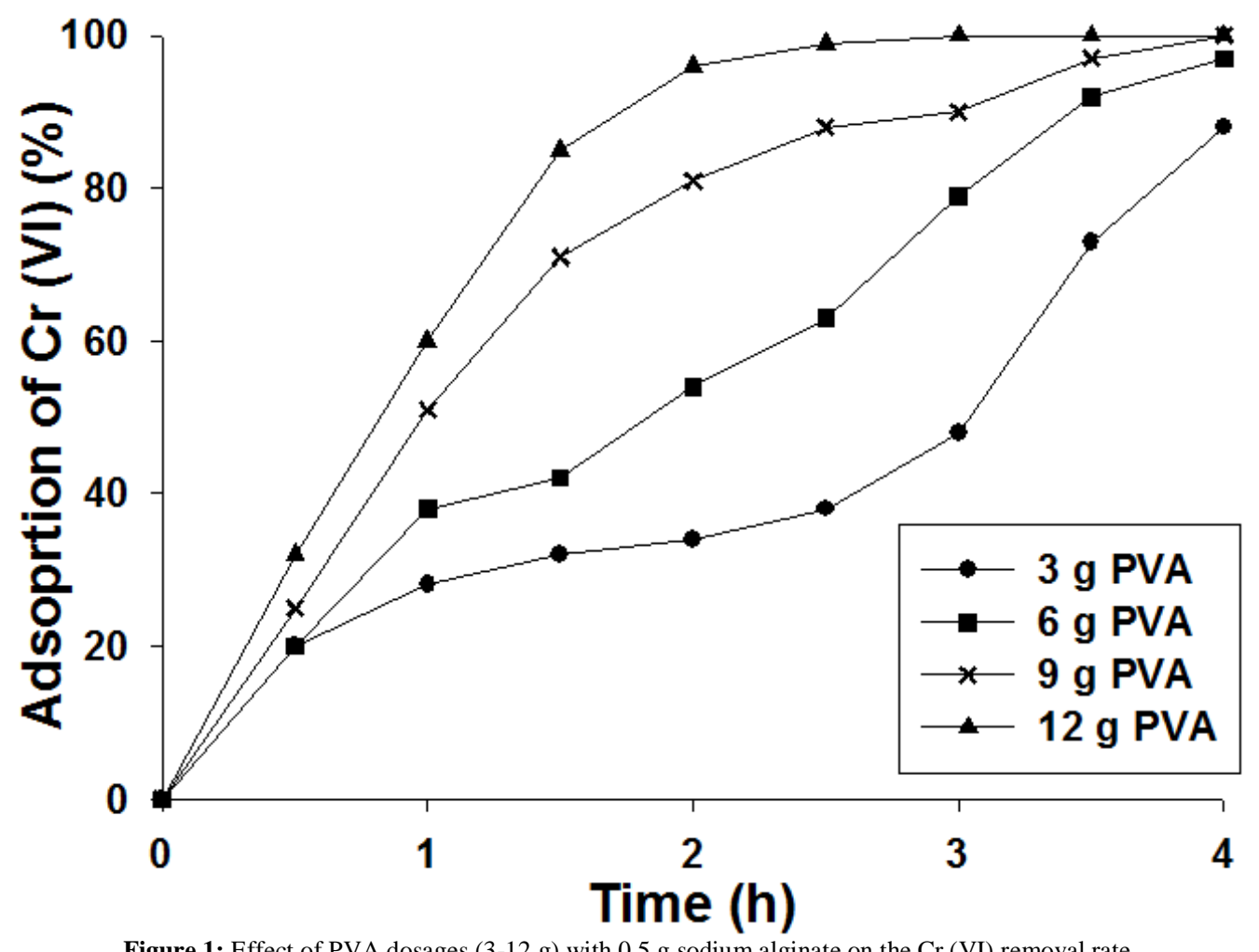

Figure 1: Effect of PVA dosages (3-12 g) with $0.5 \mathrm{~g}$ sodium alginate on the $\mathrm{Cr}$ (VI) removal rate.

Figure 2 shows the $\mathrm{Cr}(\mathrm{VI})$ adsorption rate of PVA-alginate beads produced from $12 \mathrm{~g}$ PVA and varying dosages of sodium alginate (0.5-2.5 g). It could be inferred that the $\mathrm{Cr}$ (VI) adsorption efficiency was increased in tandem with the increased dosage of sodium alginate. At dosage $0.5 \mathrm{~g}$ of sodium alginate, the $\mathrm{Cr}$ (VI) was completely removed after 3 hours of illumination period. The time for removing $\mathrm{Cr}$ (VI) was shortened to 2 hours when the dosage of sodium alginate was 1 and $2 \mathrm{~g}$. A rapid adsorption was observed when the dosage of sodium alginate was increased to $2.5 \mathrm{~g}$, the time needed to completely remove $\mathrm{Cr}$ (VI) in aqueous solution can be achieved within 1.5 hours. It is well known that sodium alginate is mainly consists of guluronate $(\mathrm{G})$ and mannuronate $(\mathrm{M})$. The $\mathrm{M}$ residues were contributed mainly to the cation exchange of heavy metals. Moreover, the hydroxyl group in sodium alginate also possess the capacity for cation exchange, hence enhanced the Cr (VI) adsorption efficiency ([3]; [18]). The availability of ion exchangeable sites and active sites for $\mathrm{Cr}$ (VI) were greatly increased due to the increase sodium alginate dosage [7]. Thus, the adsorption efficiency of PVA-alginate beads increased with the increased dosage of sodium alginate.
It is necessary to report the dosage of PVA and sodium alginate was not increased to more than $12 \mathrm{~g}$ and $2.5 \mathrm{~g}$, respectively due to the fact there is tendency of PVA-alginate gel with high viscosity to be formed at a higher dosage thus it difficult to produce spherical beads. Hence, it could be concluded that the optimum dosage to produce spherical PVAalginate beads are $12 \mathrm{~g}$ of PVA and $2.5 \mathrm{~g}$ of sodium alginate. Moreover, a rapid metal uptake rate was observed after the first 1.5 hours, or known as first stage of heavy metal adsorption. The adsorption behaviour is mainly due to the abundant active sites initially available on the adsorbent surface. Afterwards, the metal adsorption rate was followed by a slower metal uptake rate until a stable equilibrium was achieved and was spread over a considerably lower period of time, which was known as the second stage of heavy metal adsorption. In this stage, adsorption occurred less efficiently due to the gradual occupancy of active sites [14]. This type of adsorption pattern was observed in several studies done by other researchers on various heavy metals or adsorbents ([4]; [11]; [13]). 


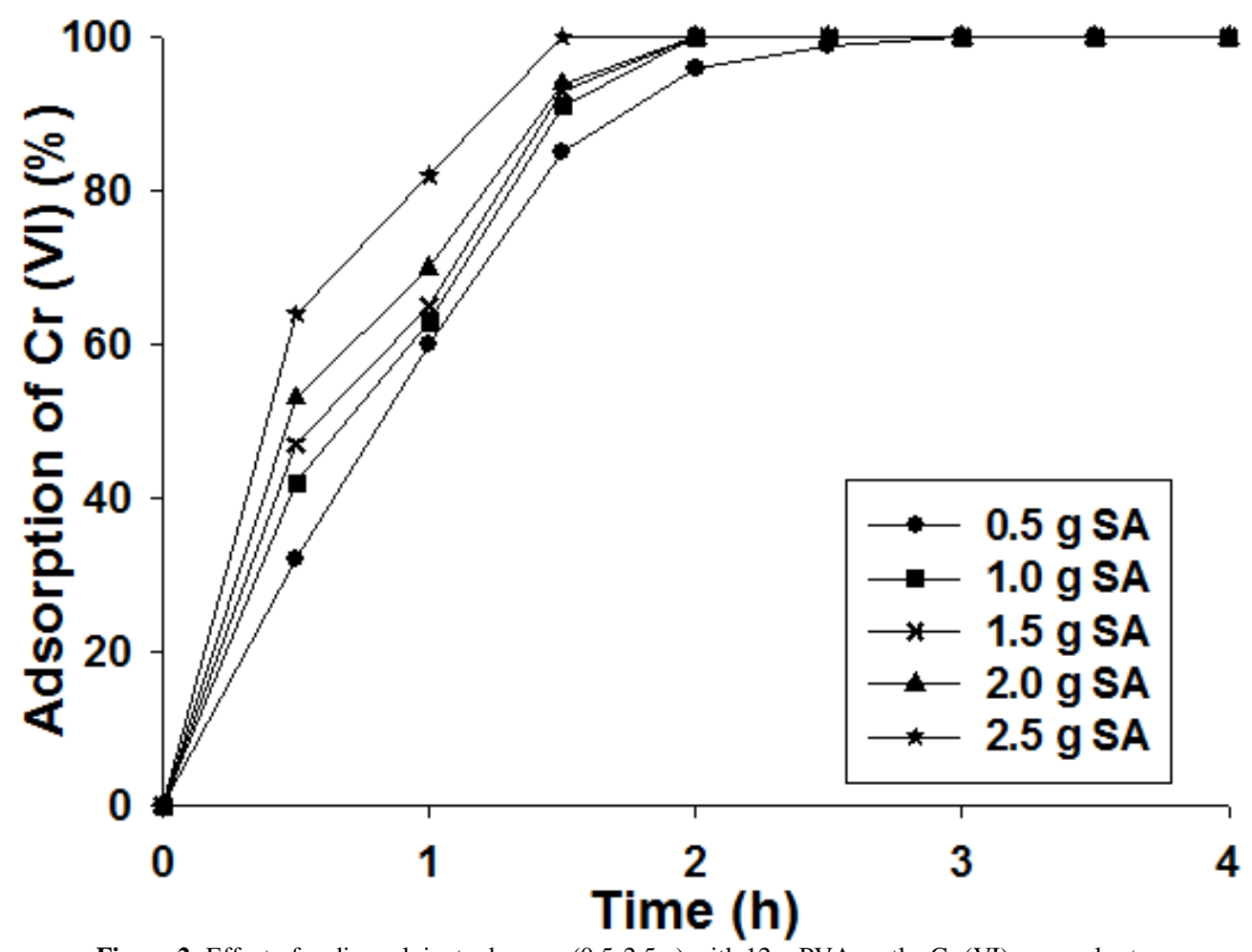

Figure 2: Effect of sodium alginate dosages (0.5-2.5 g) with $12 \mathrm{~g}$ PVA on the $\mathrm{Cr}$ (VI) removal rate.

Figure 3 shows the FESEM micrographs of $12 \mathrm{~g}$ PVA-2.5 g alginate beads before and after 4 hours of $\mathrm{Cr}$ (VI) adsorption. The smooth surface was observed before $\mathrm{Cr}$ (VI) adsorption. In contrast, the surface of PVA-alginate beads drastically changed after Cr (VI) adsorption. It can be seen that, the surface of beads become rough along with irregular form and cracks. This occurred mainly due to the chemical and physical damage during the adsorption of the heavy metal, as similarly reported by [17].

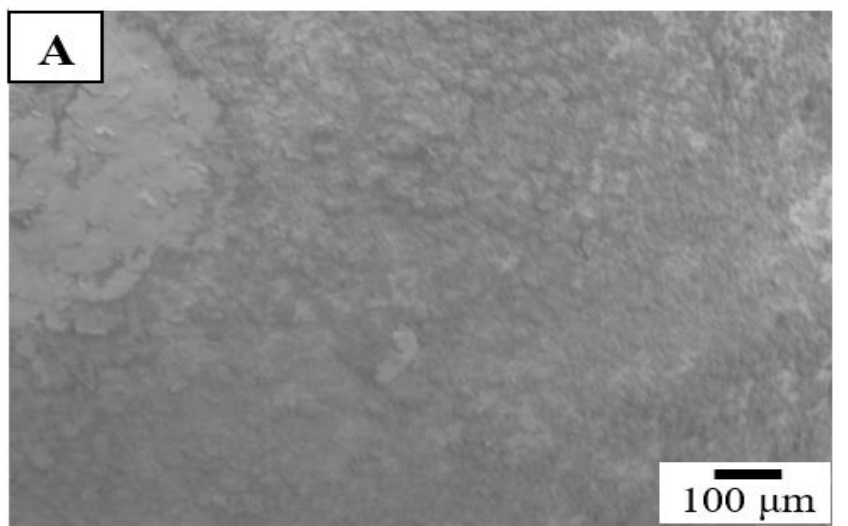

The EDS analysis of the various elements on the surface of $12 \mathrm{~g}$ PVA-2.5 $\mathrm{g}$ alginate beads is tabulated in Table 1. It can be concluded that no chromium was found on the surface of beads before the adsorption experiment. After the adsorption experiment, $\mathrm{Cr}$ was detected on the surface with mass content of $0.11 \%$, indicating that the adsorption of $\mathrm{Cr}(\mathrm{VI})$ onto PVA-alginate beads occurred via diffusion through the surface of beads. [12].

Figure 3: FESEM images of $12 \mathrm{~g}$ PVA-2.5 g alginate beads (A) before adsorption, and (B) after 4 hours adsorption.

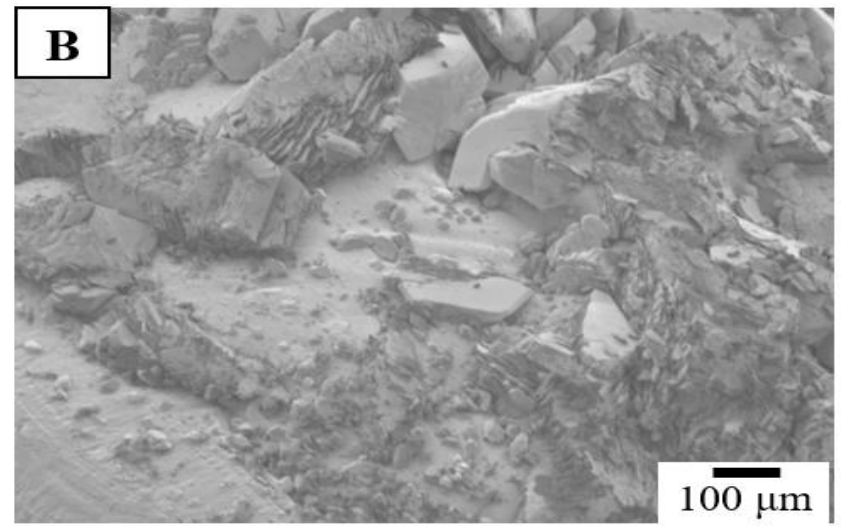

Table 1: ED's analysis of $12 \mathrm{~g}$ PVA-2.5 g alginate beads before and after 4 hours adsorption of $\mathrm{Cr}(\mathrm{VI})$

\begin{tabular}{|l|c|c|}
\hline \multirow{2}{*}{ Element } & \multicolumn{2}{|c|}{ Mass content (\%) on the surface of PVA-alginate beads } \\
\cline { 2 - 3 } & Before adsorption & After adsorption \\
\hline Carbon & 27.97 & 53.45 \\
\hline Oxygen & 49.23 & 39.72 \\
\hline Sodium & 3.21 & 0.01 \\
\hline Chromium & 0.00 & 0.11 \\
\hline Calcium & 18.67 & 6.66 \\
\hline Bromine & 0.92 & 0.05 \\
\hline
\end{tabular}




\section{Conclusions}

The adsorption rate of $\mathrm{Cr}$ (VI) on PVA-alginate beads was found to be strongly dependent on the corresponding dosages of PVA and sodium alginate. It was observed that the Cr (VI) adsorption [11 capacity increased with increase of PVA and sodium alginate. Additionally, the results showed that 12 g PVA-2.5 g sodium alginate beads demonstrated the greatest $\mathrm{Cr}$ (VI) adsorption capacity as the $\mathrm{Cr}$ (VI) was completely removed from the aqueous solution in 1.5 hours. Moreover, the results also revealed that the surface morphology of PVA-alginate beads had drastically changed to irregular forms with cracks after the adsorption process owing to the physical and chemical effects during the adsorption process. Concisely, PVA-alginate beads have great potential for the treatment of wastewater containing $\mathrm{Cr}(\mathrm{VI})$.

\section{References}

[1] Abu-Saied, M. A., R. Wycisk, , M. M. Abbassy, , G. A. El-Naim,, F. El-Demerdash, , M. E. Youssef, H. B. Bassuony and P. N. Pintauro, 2017. Sulfated chitosan/PVA absorbent membrane for removal of copper and nickel ions from aqueous solutionsFabrication and sorption studies. Carbohydrate Polymers, 165:149. 158.

[2] Arbabi, M., S. Hemati and M. Amiri, 2015. Removal of lead ions from industrial wastewater: A review of Removal methods. International Journal of Epidemiologic Research, 2(2):105-109.

[3] Bée, A., D. Talbot, S. Abramson and V. Dupuis, 2011. Magnetic alginate beads for $\mathrm{Pb}(\mathrm{II})$ ions removal from wastewater. Journal of Colloid and Interface Science, 362(2): 486-492.

[4] Dashtdar, H., M. R. aman Murali, A. A mir Abbas, A. M. ahmod Suhaeb, L.Selvaratnam, L. X. Tay and T. Kamarul, 2015. PVAchitosan composite hydrogel versus alginate beads as a potential mesenchymal stem cell carrier for the treatment of focal cartilage defects. Knee Surgery, Sports Traumatology, Arthroscopy : Official Journal of the ESSKA, 23(5):1368-1377.

[5] Draget, K. I., 2009. Alginates. Handbook of Hydrocolloids. Woodhead: Cambridge, UK.

[6] Gok, C. and S. Aytas, 2009. Biosorption of uranium(VI) from aqueous solution using calcium alginate beads. Journal of Hazardous Materials, 168(1):369-375.

[7] Idris, A., E. Misran, N. Hassan, A. A. Jalil and C. E. Seng, 2012. Modified PVA-alginate encapsulated photocatalyst ferro photo gels for $\mathrm{Cr}(\mathrm{VI})$ reduction. Journal of Hazardous Materials, 227-228, 309-316.

[8] Kadajji, V. G. and G. V. Betageri, 2011. Water soluble polymers for pharmaceutical applications. Polymers, 3(4):1972-2009.

[9] Kumar, M., B. P. Tripathi and V. K., Shahi, 2009. Crosslinked chitosan/polyvinyl alcohol blend beads for removal and recovery of
Cd(II) from wastewater. Journal of Hazardous Materials, 172(2-3), 1041-8.

[10] Kyzas, G. Z., J. Fu and K. A. Matis, 2013. The change from past to future for adsorbent materials in treatment of dyeing wastewaters. Materials, 6(11):5131-5158.

Mahdavinia, G. R., S. Mousanezhad, H. Hosseinzadeh, F. Darvishi and M. Sabzi, 2016. Magnetic hydrogel beads based on PVAsodium alginate/laponite RD and studying their BSA adsorption. Carbohydrate Polymers, 147:379-391.

[12] Majidnia, Z. and M. A. Fulazzaky, 2017. Photocatalytic reduction of $\mathrm{Cs}(\mathrm{I})$ ions removed by combined maghemite-titania PVAalginate beads from aqueous solution. Journal of Environmental Management, 191:219-227.

[13] Majidnia, Z., and A. Idris, 2015a. Evaluation of cesium removal from radioactive waste water using maghemite PVA-alginate beads. Chemical Engineering Journal, 262:372-382.

[14] Majidnia, Z. and A. Idris, 2015b. Photocatalytic reduction of iodine in radioactive waste water using maghemite and titania nanoparticles in PVA-alginate beads. Journal of the Taiwan Institute of Chemical Engineers, 54:137-144.

[15] Manap, N. and N. Voulvoulis, 2016. Data analysis for environmental impact of dredging. Journal of Cleaner Production, 137:394-404.

[16] Ngah, W. S. W. and S. Fatinathan, 2008. Adsorption of $\mathrm{Cu}(\mathrm{II})$ ions in aqueous solution using chitosan beads, chitosan-GLA beads and chitosan-alginate beads. Chemical Engineering Journal, 143(13):62-72.

[17] Ngah, W. S. W. and S. Fatinathan, 2010. Adsorption characterization of $\mathrm{Pb}$ (II) and $\mathrm{Cu}$ (II) ions onto chitosantripolyphosphate beads: Kinetic, equilibrium and thermodynamic studies. Journal of Environmental Management, 91(4):958-969.

[18] Papageorgiou, S. K., F. K. Katsaros, E. P. Kouvelos, J. W. Nolan, H. Le Deit and N. K. Kanellopoulos, 2006. Heavy metal sorption by calcium alginate beads from Laminaria digitata. Journal of Hazardous Materials, 137(3):1765-1772.

[19] Shi, T., D. Yang, H. Yang, J. Ye and Q. Cheng, 2017. Preparation of chitosan crosslinked modified silicon material and its adsorption capability for chromium(VI). Applied Clay Science, 142:100-108.

[20] Vijayalakshmi, K., T. Gomathi, S. Latha, T. Hajeeth, and P. N. Sudha, 2016. Removal of copper(II) from aqueous solution using nanochitosan/sodium alginate/microcrystalline cellulose beads. International Journal of Biological Macromolecules, 82:440-452.

[21] Vroman, I. and L. Tighzert, 2009. Biodegradable polymers. Materials, 2(2): 307-344.

[22] Yu, J., J. Wang and Y. Jiang, 2016. Removal of Uranium from Aqueous Solution by Alginate Beads. Nuclear Engineering and Technology, 49(3): 534-540.

[23] Zhu, K., Y. Duan, F. Wang, P. Gao, H. Jia, C. Ma and C. Wang, 2017. Silane-modified halloysite/Fe3O4 nanocomposites: Simultaneous removal of $\mathrm{Cr}(\mathrm{VI})$ and $\mathrm{Sb}(\mathrm{V})$ and positive effects of $\mathrm{Cr}(\mathrm{VI})$ on $\mathrm{Sb}(\mathrm{V})$ adsorption. Chemical Engineering Journal, 311:236-246. 